\title{
Service Provider Views of Oxycontin Use on an Indian Reservation: Traumatic Effects on the Tribal Community
}

\author{
Sandra L. Momper, Mary Kate Dennis, \& Amelia C. Mueller-Williams
}

\begin{abstract}
This qualitative research study on a Great Lakes Indian reservation used semistructured interviews of American Indian $(n=8)$ and non-American Indian $(n=2)$ providers of behavioral and physical health services to elicit views of Oxycontin use. We gathered data on existing substance abuse services including accessibility, cultural appropriateness, service strengths and weaknesses, barriers to treatment, and treatment needs. Results indicated a high prevalence of the use of Oxycontin, with traumatic effects on families and the tribal community such that the providers were overburdened with their dual role as service providers and caretakers in their own community. Implications for social work practice are discussed.
\end{abstract}

\section{IMPLICATIONS FOR PRACTICE}

- $\quad$ Awareness of the growth in the use and abuse of Oxycontin on American Indian reservations can assist social workers in providing appropriate substance abuse interventions.

0 ne of the most significant public health issues in the United States over the past decade has been the marked rise in the nonmedical use and abuse of prescription drugs (Compton \& Volkow, 2006). Nearly 7 million Americans are abusing prescription drugs - more than the number who are abusing cocaine, heroin, hallucinogens, ecstasy, and inhalants combined. That number was 3.8 million in 2000 , an $80 \%$ increase in just 6 years (U.S. Drug Enforcement Administration [DEA], 2010). In 2010, the number of new nonmedical users of Oxycontin aged 12 or older was 598,000, with the average age of first use being 22.8 years among 12to 49-year-olds (Substance Abuse and Mental Health Services Administration [SAMHSA], 2011). In 2004 the National Drug Threat Survey indicated that a high percentage of state and local law enforcement agencies in the Midwest reported that oxycodones (Oxycontin, Percocet, and Percodan; 60.9\%) and hydrocodones (Lorcet and Vicodin; 51.8\%) were commonly diverted and abused in their jurisdictions (U.S. Department of Justice [DOJ], 2004). The number of deaths related to prescription opioids increased $98 \%$ from 2002 to 2006 (DOJ, 2010).

In a 2007 qualitative study, data were collected on this Midwest Indian reservation of approximately 1,900 people, and results indicated that there was a substantial increase in the nonmedical use of prescription opioid analgesics; numerous negative consequences to individuals, families, and the tribe; few to no treatment resources; and significant barriers to treatment (Momper, Delva, \& Reed, 2011). In 2009, a follow-up study consisting of semistructured interviews of service providers gathered their perceptions of the use and abuse of Oxycontin on this reservation. A subsequent survey of 400 tribal mem- bers found that $30 \%$ of respondents reported having used Oxycontin in their lifetime.

\section{Theoretical Perspective: Historical Trauma}

Historical trauma is both a description of trauma responses and an explanation for them (Evans-Campbell, 2008). Historical trauma is defined as a cumulative and collective emotional and psychological injury over one's life and across generations, resulting from a cataclysmic history of genocide (Brave Heart, 1999b; Brave HeartJordan, 1995). It manifests itself by "depression, self-destructive behavior, substance abuse, identification with ancestral pain, fixation to trauma, somatic symptoms, anxiety, guilt, and chronic bereavement" (Brave Heart, 1999b, p. 111) resulting in negative health outcomes (Estrada, 2009). Trauma responses can be psychological and carried forward to future generations, resulting in substance abuse, for example (Brave Heart, 1999a; Brave Heart-Jordan, 1995). One belief regarding historical trauma is that it impacts the individual, the family, and the community (Evans-Campbell, 2008). The individual may have debilitating symptoms affecting both physical and mental health (Barocas \& Barocas, 1980), families may have impaired communication or experience stress in parenting (Brave Heart \& DeBruyn, 1998), and the community may experience a loss of cultural values, substance abuse, and physical illness (Duran, Duran, Brave Heart, \& Yellow Horse-Davis, 1998). We posit that historical trauma has occurred and is pervasive on all levels on this reservation, as is evidenced by the stories of the providers of substance abuse services.

\section{Setting}

The reservation land mass is 124,234 acres, only $5 \%$ of which is inhabited by the tribal community; the rest is undeveloped and wild. There are 7,335 tribally enrolled members; 1,044 reside on the reservation. However, there are a total of 2,738 residents. Not all residents are en- 
rolled, which is the process of providing proof of lineage and then being voted in by tribally enrolled members. Most, however, are socially considered members of the community. This is a small homogeneous setting in which mostly everyone knows everyone else. Most of the people live in a small area on the upper end of the reservation on either side of the highway that traverses the reservation. The tribe has a van for transportation, and the local town also provides van transportation to reservation residents. The tribe manages the hotel, casino, small grocery store, gas station, social service center, elderly center, health center, housing office, Head Start program, community center, Boys \& Girls Club, fire station, recycling center, fish hatchery, and legal departments.

\section{Methods}

This mixed-method research was conducted in two phases in 2009. In Phase 1, the first author used a nonprobability purposeful sampling methodology to select and conduct semistructured interviews of behavioral and physical health service providers $(N=10)$. Data were collected on participants' views of substance use and abuse, particularly Oxycontin; treatment availability and appropriateness; barriers to treatment; and treatment needs. Participants filled out a brief questionnaire with age, gender, services provided, role as service provider, and length of time the relationship existed with the reservation community. Informed consent was obtained, sessions were recorded, and \$20 was provided to the participants for their willingness to share information. Both tribal and IRB (institutional review board) approvals were received. In Phase 2, informed by these data, we designed a quantitative survey to assess the prevalence of Oxycontin use as well as information on available treatment and administered it to community members $(N=400)$. We report on Phase 1 in this article.

\section{Characteristics of Service Providers}

In all, 10 providers of service on $(n=8)$ and off $(n=2)$ the reservation were interviewed. Interviewees ranged in age from 50 to 70 years old; eight were female; and eight were tribally enrolled members. Interviewees were composed of community health workers, an Indian child welfare worker, alcohol and other drug abuse counselors, and a social service worker. They reported that they had between 5 months and 24 years of service in their roles.

\section{Analyses}

The interview data were recorded and transcribed verbatim and then reviewed by the first author for accuracy. Then the authors used a content analysis approach, whereby we first became familiar with the data by reading through all interview transcripts (Tutty, Rothery, \& Grinnell, 1996). The purpose of using this approach was to be able to analyze the text to define common themes in participant views of Oxycontin use and abuse in the community (Berg, 1989, 2004). During the next stage of coding we reread the transcripts to define categories from repeating ideas. We met to review the independently coded data and agreed on the categories. We then discussed and reached agreement on the categories and resulting themes reported here. Themes identified by participants were consistent throughout the interviews.

\section{Results}

The information gathered from the interviews with the service providers revealed commonly known information about Oxycontin use and abuse-there is a high prevalence of Oxycontin use on the reservation. As one chemical dependency counselor shared,

It is a problem here on the reservation. I know firsthand, almost every single new client that I get, you know, has got some history with Oxycontin or some type of narcotics. (R2)

The impressions offered by the service providers about the population of people on the reservation who use Oxycontin varied by position and were informed largely by the segment of the population with whom they work regularly. The child welfare worker felt that the problem was "particularly acute" among women between ages 18 and early 30s (R6).

Others cited that the teenagers were beginning to use, with one service provider observing teenagers gathering plastic drinking straws from a food stand at a community Pow Wow at such a rate that it caused attention, worry, and alarm that the youth were using them for substance use. These varying ideas of who is using show that accurate information about the use of prescription pills on the reservation is imperative for informing the practice of each provider and for effectively addressing the problem from multiple angles.

Aware of the problem Oxycontin was creating on the reservation, the tribal government passed a resolution limiting the criterion for prescriptions and discouraging local pharmacies from supplying the medication by not reimbursing them for the prescriptions filled for drug seekers. Additionally, the tribal health clinic and pharmacy no longer fill prescriptions of Oxycontin. Given that substance abusers can be resourceful in acquiring the pills, the director of health services shared the tribes' strategy in limiting the availability on the reservation:

Our physicians and our pharmacists were not to readily prescribe or provide this to patients unless they fit within a specific category, and 
that is, trauma victims, people who have been in accidents, terminal illness was another one....Prior to that, Oxycontin was readily available on the reservation, and even though we've attempted to control it, people are still getting prescriptions from physicians and clinics beyond the boundaries of the reservation...they cannot get these prescriptions filled at our pharmacy. (R1)

They have created a system where they have, over time, built relationships with off-reservation pharmacies where the pharmacies contact the tribal health clinic for prescription confirmation. There have been pharmacies where tribal members have filled prescriptions and claimed that the reservation contract health system would pay for it. The reservation health system has held their ground and built a reputation for having upheld their policy on Oxycontin and not reimbursed pharmacies for illegal prescriptions. (R1)

Beyond these efforts, the services provided are adult inpatient services at a local off-reservation hospital, which is usually 3 days of detoxification or a 90 -day stay at a site that is much farther away from the reservation; a halfway house on a nearby reservation; aftercare counseling when a client is discharged from a 30-day inpatient treatment center; intensive outpatient programs for individuals and groups, which include families; a local Suboxone program in a border town near the reservation where clients receive outpatient counseling and Suboxone to assist in withdrawal from opioids; adolescent and adult outpatient counseling; an outpatient alcohol/drug abuse program that offers prevention services for youth, but no inpatient treatment for this age group; support groups for men and women; and a recovery talking circle led by a Native American substance abuse counselor. The list is impressive; however, providers and users believe that longer inpatient stays are needed but are costly-more than $\$ 6,000$ per month per personand the tribal health center does not receive dollars for treatment or mental health services through the Indian Health Service. The programs offered can only service a limited number of people, and there is usually a very long waiting list to become enrolled.

\section{Effects on the Reservation Community}

Oxycontin use on the reservation has stressed many of the community resources that are already limited and underfunded. Oxycontin users also affect the general feeling of safety and security in the community, because users have become desperate in acquiring the pills and so have been breaking into the homes of the elderly and terminally ill.
And, I mean, and these people that are...we've had so much...[a] couple break-ins in our rez ${ }^{1}$ here, huh? Remember? And they know what they're looking for. I mean, we had a break-in down where I live, in [inaudible] down there with an elderly woman. And she... was on all kinds of medication. And they went in there and they looked....they left all the medication. They took just one pill that had some kind of narcotic in it. (R3)

One social problem that has arisen from Oxycontin use on the reservation is the effect on the elders. Culturally, elders are respected and revered members of $\mathrm{Na}$ tive American society. Often they are cared for by their younger family members who now are burdened with having to make trips to the off-reservation pharmacy to acquire medication and are scrutinized to make sure they are not diverting these medications for illegal use. Elders living alone and the very ill need special attention, and care and concern for their safety is crucial.

Conversely, there were elders and other middle-aged members of the community who had resorted to selling their own pills to substance abusers on the reservation. One male participant offered an illustrative example:
And there are some instances where some...I don't know whether you would call them elder or middle age, when they get their drugs, they turn around and then they sell them. And then pretty soon they're right back at the pharmacy saying, "I need more because I'm running out." And at the rate they're running out, why, you know something's wrong here...that's how they start to find out that they were selling them. (R7)

Given that the Oxycontin pills have a street value of $\$ 10$ per milligram, some pills sold for $\$ 80$ per pill. The elders were trying to augment their incomes, which can often be meager, by selling their prescriptions. The dire financial situation on the reservation caused a social and cultural shift as the elders, revered leaders in the community, were now contributing to the problem of substance abuse on the reservation. This demonstrates how deeply the use of prescription pills has permeated the reservation community. Thus treatment services will have to adapt to older adults and their needs. Other adults who have experienced physical injury as a result of accidents were also caught in a cycle of selling pills for financial reasons, buying black market pills to stave off withdrawal and pain symptoms, and then having to sell pills when they get their prescription filled to pay the debt for the acquired pills. The high price of the pill draws in people with legitimate prescriptions to enter the drug trade.

\footnotetext{
${ }^{1}$ Rez is a colloquial term for reservation.
} 
The health complications associated with the prolonged prescription pill abuse stress the already underfunded health care system. Current and former Oxycontin users are sometimes easily identified, as one provider pointed out:

\section{That you kind of tell who is on because of dental issues because we have to transport them to the dentist....we pretty much know around the reservation who uses and who doesn't use. And we've...I have noticed, anyway, that the people that we transport for dental [appointments] were Oxy users. (R3)}

The use of Oxycontin brings about health complications that exacerbate health services, which are then unable to meet the needs of the community, now that they have to keep up with the demand caused by side effects of drug use, like dental services. An emergency medical technician (EMT) also cautioned that when first responders are called for an overdose and are able to reach the individual in time to intervene, "Even if they survive, they have a lot of heart damage" (R10). Often when responding to a known user, they are aware that the physical toll the drugs have taken is often a complicating factor for a population that already struggles with well-documented health disparities and chronic diseases.

Deaths from Oxycontin ripple through the tightly knit reservation community and leave a lasting impact as the families and friends pick up the pieces for the children left behind. The grief and loss associated with these deaths is carried not only by the family members but also in the broader reservation community. Deaths on the reservation as a result of Oxycontin were shared by an EMT:

Yep. I've responded to some deaths where we know the folks were prescription, narcotic prescription, drug users....Last one we just went to where there was a death...he was 40 [or] 42. (R10)

Overdoses leading to death cause families to scramble to provide for funeral costs, leave children without parents, and put the broader community in a state of grief. This tightly knit community feels the pain of each loss, and as the deaths happen more frequently, the losses are felt more deeply. Accidental overdoses are always a risk as prescription drug users often take multiple varieties of pills and alcohol. The mixing of prescriptions with alcohol led to deadly consequences for one tribal member who was only 31 years old and had two children. Several of the service providers shared the story, and one outpatient counselor was related to the woman, who had started a methadone treatment and was attempting to get her life together and be reunited with her husband, but was struggling with addiction. The counselor shared that
I actually had a niece who died last week. She died in Milwaukee....So, he [her husband] was only home a week. Then he...woke up one morning, and...he rolled her over, and she was cold, [and her] lips were blue. (R8)

It is significant that even though she died in a city a few hours away from the reservation, her death was felt by the reservation community when she was brought home to be buried. These deaths stress families, because of the children left without parents, and an already stretched community to fill the gaps left behind. One elder living on the reservation who is aware of the families who are struggling and knows the children's birthdays organizes and prepares the dinner and cake for the children's parties. Many times these children are not her relatives, but she wants to alleviate the stress and provide an opportunity for the children to have joy and celebration.

\section{Effects on Children and Families}

A major issue the community faces is that when a mother is using, she becomes "apathetic toward taking care of [her] kids" (R6). One service provider cited examples of mothers who were using and were not taking care of their children. There are increasing numbers of children being removed from the home. Both a child welfare worker and a chemical dependency counselor shared that there were a large number of Oxycontin users with children in foster care. The child welfare office on the reservation handles a variety of cases where mothers are living with addiction to Oxycontin, are being jailed for prescription drug fraud and possession, and are neglecting their children.

Well, ah, from the Indian child welfare standpoint, we want to ascertain the environment for the children that are involved. A lot of times there's young children involved. They bring the children, maybe 1 year, $1^{1 / 2}$ years of age with them when they get the prescription filled....then we have to look at their home environment, what's going on and things like that. But as far as...being charged... we let the police authorities handle that. (R6)

The close relatives of the children are first sought out to place the children, or they are placed in foster homes on the reservation. The success rate of these children being reunified with their parents is "maybe 20\%, 30\%" (R6). Permanent adoption is a choice of last resort. Children become casualties in the addiction on prescription drug use, which affects the entire community as the children are being raised by family members or, worse, moved away from the reservation community into foster care. There are many middle-aged grandmothers and aunts raising children as a result of prescription drug use. 
The service providers offered insights into their personal lives, more than their professional lives at times, because several of them are affected by Oxycontin usage by their adult children. These providers are often left in a stressful situation where they are working full time, dealing with the chaos of addiction, and addressing the needs of grandchildren. Even great-grandmothers are involved in the raising of the children of addicts, despite their own physical challenges. The following respondent was in a wheelchair as the result of being hit by a drunk driver years ago. She also provided assistance to her aging mother who was in her 80 s.

You know, I've been trying to keep an eye on everything. But that's how she [her granddaughter who uses] ended up eventually losing her kids....I have custody of them. (R5)

The children born to addicts struggle not only with having parents whose attention is on the next pill, but also with their own ability to develop and thrive. These children are often easily recognized, as one WIC (Special Supplemental Nutrition Program for Women, Infants, and Children) consultant shared experiences of working with children who are not at the appropriate stages developmentally. The grandmothers and other relatives raising these children may not be prepared to adequately address behavioral and developmental issues without access to proper resources. Thus the children and grandmothers continue to be stressed as they try to make the best situation possible in the absence of the addicted parents.

The mothers of the adult children who were users, of which there were several in this study, were distracted by their own personal turmoil about addiction in their children, and they often interjected these stories into the interviews. The emotions associated with addiction often led the mothers to question themselves about where they went wrong. They shared the details of the chaos and their contributions to it, including carrying the burden of helping their children get sober, because they lived in a resource-poor environment and wanted to help the kids.

When he got out of treatment, it was like, "Ma, I have to go to...my counseling now tonight. I don't have a ride." I'm like, Jesus Christ, I've got to leave my house and bring you up there, then pick you up, you know. But...I was yelling at him a couple times. I thought, oh my God, I have to... you know...be supportive. (R3)

Currently, there are no services that support the families in working through their own experiences, thus leaving the middle-aged generation of women as the major resource in this community-they are gainfully employed, raise grandchildren, offer support to the ad- dicts, raise their other children, help with their elder parents, try to maintain their own health and wellbeing, and are often the glue holding the families and community together. They are in need of support in the form of real services where they can share their burdens and learn healthy boundaries and repair the effects of the addiction on their families.

\section{Discussion}

One belief regarding historical trauma is that it impacts the individual, the family, and the community (EvansCampbell, 2008). The effects of addiction on this reservation are widespread. The individual struggles with the addiction to Oxycontin and what it does to their ability to parent and work. Guilt and remorse are pervasive. In a prior study on this reservation (Momper et al., 2011), one participant who used Oxycontin and wanted to help her daughters who also used stated: "You know, I would love to help my daughters and get them off them, but I can't do it." Mothers admitted in that study that they were emotionally abusive to their kids during withdrawal, and one young mother broke down and cried during the group session because she loved her children. Treatment resources were limited, and/or far away and many mothers were reluctant to leave their children for an inpatient stay. What is especially troubling is that only a small proportion (4\%) of American Indian/Alaska Native facilities provided opioid treatment programs, that is, programs that dispense methadone or buprenorphine to treat addiction to opiates (SAMHSA, 2009).

At the family level children are raised without proper care, and grandmothers or other female relatives are placed in positions where they intervene, as is culturally appropriate, and raise the children of those addicted to Oxycontin. The relatives, then, have to also assist the addict in being able to get to treatment resources, which are not always easy to access or not readily available. Additionally, the children exhibit physical and emotional effects of the drug, especially children born to mothers who continue to use. The physical side effects witnessed are much like those observed in Oxycontin users, such as nausea and vomiting, ileus, and constipation (Berde \& Nurko, 2008). The farreaching consequences will not all be seen for years. After a cursory review of the literature, few to no peer-reviewed journals are reporting on the long-term aftereffects of opioid use on children born to users. The grandmothers and great-grandmothers may not be equipped to handle the special health needs of these children, because the children are coping with the effects of exposure to prescription drugs and the emotional issues related to abandonment by their parents. Given that the stressors of raising these grandchildren can exacerbate the health issues of the grandmothers, health professionals should be prepared to provide more emotional consideration. 
Mental health service providers should be aware of the strain on families and find creative ways to alleviate the effects on these families. At the community/tribal level social services are burdened as they are put in the position of having to assist the individuals and the families in many ways as monies are not used for resources like food, electricity, or rent, and children are in danger of being hungry or without housing or heat. Treatment resources are limited because many are only available off the reservation, have long waiting lists, and are not able to handle the numbers of Oxycontin users that are on the reservation. Additionally, fears of reporting exist on many levels. On a nearby reservation a federal raid occurred, and the sentences given to the young Indian men were harsher than those given to non-Indians. This response led the community to once again realize the precarious relationship that exists between the tribe and the federal government. The reservation is a community where everyone knows everyone else, and if someone reports the use or delivery of Oxycontin, retribution could occur. The elders are at a particular risk; if anyone finds out that they have a debilitating disease that would require Oxycontin, they have to be extra careful about whom they tell and have to be aware of the need to hide the drugs and lock up their houses, things they are not accustomed to doing. The most lasting detrimental effect is the deaths resulting from the use and abuse of Oxycontin, whether alone or in combination with other drugs and/or illnesses. When a death occurs on the reservation, everyone is involved, as it is a small, tightly knit community. As is apparent from this study, the use and abuse of prescription drugs complicate the already stressful lives of Native American people living on the reservation.

\section{Limitations}

Limitations should be noted for this study. This is a very small nonprobability purposive sample of service providers, and the results cannot be generalized to other reservations. However, it is very likely that this is occurring on other nearby reservations as well. Note that this is most likely the only study of this kind on a reservation that elicited information from service providers who were also caretakers of the children of Oxycontin users. This study led to the creation of a much needed communitywide quantitative survey of users; the results are currently being prepared for publication. Of note as well is that the use of other substances like marijuana and alcohol continues; however, the tribal participants of both the qualitative and quantitative studies report that at this time Oxycontin is the most widely abused substance.

\section{Implications for Social Work Practice}

The findings from this study have implications for social work professionals interested in the development of interventions to respond to the growing use and abuse of Oxy- contin on this and, we suspect, other Indian reservations. This study exemplifies that prescription drug use affects everyone on the reservation, as it is such a close-knit community. The formation of a committee is needed in which the social service providers, elders, family members, and users of Oxycontin meet to discuss the ways in which they can gather accurate information regarding the acquisition and trafficking of the pills and obtain accurate prevalence rates. They could work together to identify the families who are struggling and use culturally appropriate methods to support the families and users in working toward healthy living. A social worker could coordinate gatherings in a setting where all participants are able to speak freely and share honest information. Together they can learn how to maximize the use of existing resources and craft innovative solutions to minimize the effects of addiction in their community. A social worker can continue to build coalitions with agencies that interact with Indian people from this reservation. Social service providers in this study discussed obtaining funding for an intervention that is culturally sensitive to the needs of the community-either reservation based or nearby the reservation with an inclusion of traditional ways of healing. Since providers reported that other nearby reservations are experiencing the same phenomena, it may be important to hold a summit or gathering of providers to identify resources in the Midwest and to discuss best practices and interventions that have been both successful and less effective on their reservations to address this issue and suggest collaborative solutions.

\section{Conclusion}

Ultimately the findings reported here of the effects of Oxycontin use and abuse on this small reservation community are no different from other drug addiction findings in terms of the disruption of the lives of the addict; the addict's family, especially the children; and the community. The DEA (2010) reported that in 2008, approximately 2.9 million people tried an illicit drug or used a prescription drug nonmedically for the first time, representing nearly 8,000 new users per day. What is especially disturbing, however, is that the high incidence of the use and abuse of Oxycontin is yet another traumatic event occurring on rural reservations that affects an already traumatized community. The lack of resources available to treat the users is disturbing, and the lack of culturally sensitive treatment resources for American Indians is also of concern. Providers of services both on and off reservations, and in the general population as well, need to be aware of these events among users of prescription opioids and how detrimental this use is to families and communities. The long-range effects on this community are of concern as overburdened service providers and caretakers are trying to control this epidemic with few re- 
sources, both in terms of treatment services for users and mental health services for themselves and the children.

\section{References}

Barocas, H., \& Barocas, C. (1980). Separation and individuation conflict in children of Holocaust survivors. Journal of Contemporary Psychology, 38, 417-452.

Berde, C., \& Nurko, S. (2008). Opioid side effects: Mechanismbased therapy. The New England Journal of Medicine, 358(22), 2400-2402.

Berg, B. L. (1989). Qualitative research methods for the social sciences. Needham Heights, MA: Allyn \& Bacon.

Berg, B. L. (2004). Qualitative research analysis for the social sciences (5th ed.). Boston, MA: Pearson.

Brave Heart, M. Y. H. (1999a). Gender differences in the historical trauma response among the Lakota. Journal of Health and Social Policy, 10(4), 1-21.

Brave Heart, M. Y. H. (1999b). Oyate Ptayela: Rebuilding the Lakota Nation through addressing historical trauma among Lakota parents. Journal of Human Behavior in the Social Environment, 2(1-2), 109-126.

Brave Heart, M. Y. B., \& DeBruyn, L. M. (1998). The American Indian holocaust: Healing historical unresolved grief. American Indian and Alaska Native Mental Health Research, 8, 56-78.

Brave Heart-Jordan, M. Y. H. (1995). The return to the Sacred Path: Healing from historical trauma and historical unresolved grief among the Lakota (Unpublished doctoral dissertation). Smith College School for Social Work, Northampton, MA.

Compton, W. M., \& Volkow, N. D. (2006). Abuse of prescription drugs and the risk of addiction. Drug \& Alcohol Dependence, 83(1), S4-S7.

Duran, E., Duran, B., Brave Heart, M. Y. H., \& Yellow Horse-Davis, S. (1998). Healing the American Indian soul wound. In Y. Danieli (Ed.), International handbook of multigenerational legacies of trauma (pp. 341-354). New York, NY: Plenum.

Estrada, A. L. (2009). Mexican Americans and historical trauma theory: A theoretical perspective. Journal of Ethnicity in Substance Abuse, 8(3), 330-340.

Evans-Campbell, T. (2008). Historical trauma in American Indian/ Native Alaska communities: A multilevel framework for exploring impacts on individuals, families and communities. Journal of Interpersonal Violence, 23, 316-338.

Momper, S. L., Delva, J., \& Reed, B. G. (2011). Oxycontin abuse on a reservation: Qualitative reports by American Indians in talking circles. Substance Use and Misuse, 46(11), 1372-1379.

Substance Abuse and Mental Health Services Administration, Office of Applied Studies. (2009, July 9). The N-SSATS report: Substance abuse treatment facilities serving American Indians and Alaska Natives. Rockville, MD: Author. Retrieved from http://www.samhsa.gov/data/2k9/192a/192aTribalFac2k9.pdf
Substance Abuse and Mental Health Services Administration, Office of Applied Studies. (2011). Results from the 2010 National Survey on Drug Use and Health: Summary of national findings (NSDUH Series H-41, HHS Publication No. [SMA] 11-4658). Rockville, MD: Author. Retrieved from http://www.samhsa. gov/data/NSDUH/2k10NSDUH/2k10Results.htm

Tutty, L. M., Rothery, R. M., \& Grinnell, J. R. (1996). Analyzing your data: Qualitative research for social workers. Calgary, Canada: Allyn \& Bacon.

U.S. Department of Justice. (2004). American Indians and crime. Washington, DC: Perry. Retrieved from http://www.justice.gov/ otj/pdf/american_indians_and_crime.pdf

U.S. Department of Justice, National Drug Intelligence Center. (2010). National Drug Threat Assessment 2010: Controlled prescription drugs. Washington, DC: Author. Retrieved from http://www.justice.gov/archive/ndic/pubs38/38661/38661p.pdf

U.S. Drug Enforcement Administration. (2010). Fact sheet: Prescription drug abuse. Retrieved from http://www.justice.gov/ $\mathrm{dea} /$ concern/prescription_drug_fact_sheet.html

Sandra L. Momper, PhD, MSW, assistant professor, School of Social Work, Mary Kate Dennis, MSW, PhD (Cand.), Joint Degree Program in Social Work and Sociology, and Amelia C. Mueller-Williams, MSW, MPH, Schools of Social Work and Public Health, University of Michigan. Correspondence: smomper@umch.edu; University of Michigan, 1080 South University Ave., Ann Arbor, MI 48109.

Authors' note. We would like to say miigwetch (thank you) to all participants for their willingness to share their stories. This investigation was supported by grants from the University of Michigan Substance Abuse Research Center: Innovative Approaches to Investigate Aspects of Drug Use and Abuse, and the University of Michigan Vivian A. and James L. Curtis School of Social Work Research and Training Center. Its contents are solely the responsibility of the authors and do not necessarily represent the official views of UMSARC, the Curtis Center, or the University of Michigan.

Manuscript received: December 20, 2011

Revised: March 14, 2012

Accepted: March 28, 2012

Disposition editor: Susan E. Mason 